\title{
Perbandingan kadar HbA1C pada pasien DM Tipe 2 dengan frekuensi senam prolanis satu kali per minggu dan tiga kali per minggu
}

\author{
${ }^{1}$ Brigitha M. Tompira \\ ${ }^{2}$ Sylvia R. Marunduh \\ ${ }^{2}$ Ivonny M. Sapulete \\ ${ }^{1}$ Kandidat Skripsi Fakultas Kedokteran Universitas Sam Ratulangi Manado
${ }^{2}$ Bagian Fisiologi Fakultas Kedokteran Universitas Sam Ratulangi Manado
Email: b_tompira12042@yahoo.com
}

Abstract: World-wide diabetes prevalence has been rapidly increasing in the last two decades and according to the International Federations Projects, it will reach 438 million people by 2030 . HbA1c examination is a standard for measuring the long-term glycemic value in diabetic patients. A case control study shows that structured exercise is effective in lowering the HbA1c level. Prolanis is a program in Indonesia focused on managing patients with hypertension and diabetes. One of the programs that Prolanis offers is doing physical exercise for 60 minutes per week. However, American Diabetes Association stated that diabetic patients should perform at least 150 minutes of physical exercise per week. This study aimed to obtain the effect of PROLANIS exercise frequency on HbA1c. This was a field experimental study with a pre post test control group design. Data were statistically analyzed by using the T-Independent and T-dependent tests with a standard error of 5\%. There were 30 respondents divided into 2 groups: Prolanis exercise 3 times a week and once a week. The levels of HbA1c was measured before and after 4 weeks of Prolanis exercise. After the 4-weeks exercise the HbA1c levels of the once a week group rose by $0.13 \%$. Meanwhile, the 3 times per week group displayed a decreased HbA1c level by $0.04 \%$. There was a significant difference in HbA1c level before and after 4 weeks of Prolanis exercise between both groups $(p=0.032)$. Conclusion: Among diabetic patients, the 3 times of Prolanis exercise per week regimen was more effective in lowering the HbA1c levels than the 1 time of PROLANIS exercise per week regimen.

Keyword: HbA1c, type 2 diabetes melitus, prolanis

\begin{abstract}
Abstrak: Prevalensi diabetes di seluruh dunia telah meningkat jauh selama dua dekade terakhir dan menurut International Federation Projects pada tahun 2030 akan mencapai 438 juta orang. Pemeriksaan HbA1c merupakan standard dalam pemeriksaan kadar gula darah jangka panjang pada penyandang diabetes. Suatu penelitian kasus kontrol menunjukkan bahwa olahraga teratur dapat menurunkan kadar HbA1c. Prolanis adalah sebuah program dari Indonesia yang difokuskan terhadap pasien dengan hipertensi dan diabetes melitus. Salah satu program yang ditawarkan ialah senam 60 menit setiap minggu. American Diabetes Association menyatakan bahwa sekurangkurangnya pasien diabetes harus latihan fisik selama 150 menit setiap minggu. Penelitian ini bertujuan untuk mengetahui efek dari frekuensi senam terhadap kadar HbA1c. Jenis penelitian ini ialah eksperimental lapangan dengan rancangan pre post test control group design. Analisis statistic dilakukan dengan uji T tidak berpasangan dan T berpasangan (taraf kesalahan 5\%). Senam dilakukan oleh 30 responden yang dibagi dalam 2 kelompok yaitu kelompok 1 kali per minggu dan kelompok 3 kali per minggu. Pengukuran kadar HbA1c dilakukan sebelum dan setelah senam Prolanis selama 4 minggu. Setelah senam, rerata kadar HbA1c kelompok 1 kali/minggu mengalami peningkatan sebesar $0,13 \%$ sedangkan kelompok 3 kali/minggu mengalami penurunan sebesar 0,04\%. Terdapat perbedaan bermakna antara selisih kadar HbA1c sebelum dan sesudah 4 minggu senam Prolanis kedua kelompok $(p=0,032)$. Simpulan: Senam Prolanis 3 kali/minggu lebih efektif dalam menurunkan kadar HbA1c daripada senam Prolanis 1 kali/minggu.
\end{abstract}

Kata kunci: HbA1c, diabetes melitus tipe 2, prolanis 
Diabetes melitus (DM) merupakan suatu kumpulan gangguan metabolik yang memiliki karakteristik hiperglikemi dengan manifestasi berupa hilangnya toleransi karbohidrat. $^{1,2}$ DM terjadi akibat dari sejumlah faktor di mana terdapat defisiensi insulin absolut atau relatif dan gangguan fungsi insulin. ${ }^{3}$

Prevalensi diabetes di seluruh dunia telah meningkat jauh selama dua dekade terakhir dan menurut International Federation Projects pada tahun 2030 akan mencapai 438 juta orang. ${ }^{1}$ Pada tahun 2025 Indonesia akan menempati posisi keempat di seluruh dunia dengan jumlah penderita 12,4 juta orang. ${ }^{3} \mathrm{Di}$ Indonesia sendiri, Sulawesi Utara memiliki tingkat prevalensi ketiga tertinggi (1,6\%), terutama di kota Manado (6\%).

Angka prevalensi yang makin meningkat akan menempatkan diabetes sebagai penyebab utama mortalitas dan morbiditas di masa datang. ${ }^{1}$ Melihat hal ini, Program Pengelolaan Penyakit Kronis (Prolanis), sebuah program dengan format promotif preventif terintegrasi bagi penderita penyakit kronis diluncurkan oleh Askes. ${ }^{5}$ Program ini memiliki beberapa program salah satunya ialah senam Prolanis yang merupakan latihan jasmani jenis aerobik. $^{6}$ Dari beberapa pilar penatalaksanaan DM, diet dan latihan jasmani direkomendasikan pada pasien DM tipe 2 dan pemberian obat-obatan dilakukan bila

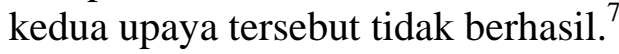

Hemoglobin pada keadaan normal tidak mengandung glukosa saat pertama kali eritrosit keluar dari sumsum tulang namun setelah masa hidup 120 hari maka hemoglobin akan terikat glukosa. Glikat hemoglobin atau HbA1c menunjukkan kadar gula darah selama 8 minggu. ${ }^{2}$ Pemeriksaan HbA1c merupakan pemeriksaan standar untuk menilai status glikemik jangka panjang dan efektif pada semua tipe penyandang DM. ${ }^{1}$

Suatu penelitian kasus kontrol menunjukkan bahwa olahraga teratur dapat menurunkan HbA1c, meningkatkan kekuatan otot dan menurunkan marker inflamasi pada lansia dengan diabetes. ${ }^{8}$
Dua penelitian sebelumnya dari Umpierre et al. dan Yang et al. menyatakan bahwa latihan aerobik lebih efektif dalam menurunkan kadar HbA1c daripada latihan beban dengan perbedaan $0,17 \% .{ }^{9}$ Hasil penelitian dari Umpierre et al. juga menyatakan bahwa latihan fisik lebih dari 150 menit per minggu lebih efektif dalam menurunkan kadar HbA1c dibandingkan dengan latihan fisik dibawah 150 menit per minggu. $^{10}$

Penelitian ini bertujuan untuk mengetahui perbandingan kadar HbA1c pada pasien DM Tipe 2 dengan frekuensi senam Prolanis 1 kali per minggu dan 3 kali per minggu”.

\section{METODE PENELITIAN}

Jenis penelitian ini ialah eksperimental lapangan dengan desain Pre-Post Cross Sectional Study dan dilaksanakan di Klinik Husada Sario Manado selama bulan November 2015 sampai dengan Desember 2015. Sampel penelitian ialah sampel darah dari 30 penyandang diabetes melitus tipe 2 yang memenuhi kriteria inklusi.

\section{HASIL PENELITIAN \\ Karakteristik dan Penyebaran Subyek Penelitian}

Pada peserta $1 \mathrm{kali} /$ seminggu, sebelum senam Prolanis rerata kadar HbA1c 8,3733\% dengan nilai minimal 5,8\% dan maksimal 12\%, sedangkan setelah diberikan latihan fisik reratanya 8,5067\% dengan nilai minimal 6,0\% dan maksimal $11,8 \%$. Nilai tertinggi peningkatan HbA1c setelah senam ialah $0,5 \%$ sedangkan penurunan $0,3 \%$. Rerata terjadi peningkatan kadar HbA1c sebesar 0,13\% setelah senam pada kelompok 1 kali/minggu.

Tabel 1. Kadar HbA1c sebelum dan sesudah senam Prolanis pada kelompok 1 kali/minggu

\begin{tabular}{ccccc}
\hline & $\mathrm{n}$ & Min & Maks & Rerata \\
\hline Pre & 15 & 5,8 & 12 & 8,3733 \\
Post & 15 & 6 & 11,8 & 8,5067 \\
HbA1c & 15 & $-0,5$ & 0,3 & $-0,13$ \\
\hline
\end{tabular}


Pada peserta $3 \mathrm{kali} /$ seminggu, sebelum senam Prolanis rerata kadar HbA1c 7,3667\% dengan nilai minimal 5,6\% dan maksimal 9,4\%, sedangkan setelah diberikan latihan fisik reratanya 7,3267\% dengan nilai minimal 5,6 \% dan maksimal 9,3\%. Peningkatan terbesar kadar HbA1c setelah latihan $0,5 \%$ dan penurunan terbesar $0,3 \%$. Rata-rata terjadi penurunan kadar HbA1c setelah latihan sebesar $0,04 \%$.

Tabel 2. Kadar HbA1c sebelum dan sesudah pada kelompok 3 kali/minggu

\begin{tabular}{ccccc}
\hline & $\mathrm{n}$ & Min & Maks & Rerata \\
\hline Pre & 15 & 5,6 & 9,4 & 7,3667 \\
Post & 15 & 5,6 & 9,3 & 7,3267 \\
HbA1c & 15 & $-0,5$ & 0,3 & 0,04 \\
\hline
\end{tabular}

Pada kelompok 1 kali/minggu, terjadi penurunan kadar HbA1c pada 4 orang (27\%), peningkatan kadar HbA1c pada 9 orang (60\%), dan tetap pada 2 orang (13\%), sedangkan pada kelompok 3 kali/minggu, terjadi penurunan kadar HbA1c pada 8 orang (53\%), peningkatan kadar HbA1c pada 4 orang (27\%), dan tetap pada 3 orang (20\%).

Tabel 3. Distribusi responden penelitian berdasarkan perubahan kadar HbA1c

\begin{tabular}{ccccc}
\hline & \multicolumn{2}{c}{1 kali/minggu } & \multicolumn{2}{c}{3 kali/minggu } \\
Status & $\mathrm{n}$ & $(\%)$ & $\mathrm{n}$ & $(\%)$ \\
\hline Menurun & 4 & 27 & 8 & 53 \\
Meningkat & 9 & 60 & 4 & 27 \\
Tetap & 2 & 13 & 3 & 20 \\
Total & 15 & 100 & 15 & 100 \\
\hline
\end{tabular}

\section{Hasil Uji Statistik}

Terdapat perbedaan bermakna antara HbA1c awal dan HbA1c akhir pada Latihan $1 \mathrm{kali} /$ minggu $(\mathrm{p}=0,034<\alpha=$ $0,05)$.

Tabel 4. Uji $\mathrm{T}$ berpasangan kelompok 1 kali/minggu

\begin{tabular}{cc}
\hline & Sig. (1-tailed) \\
\hline HbA1c Awal - & \\
HbA1c Akhir & .034 \\
\hline
\end{tabular}

Tidak terdapat perbedaan bermakna antara HbA1c awal dan HbA1c akhir pada latihan $3 \mathrm{kali} /$ minggu $(\mathrm{p}=0,258>\alpha=$ $0,05)$.

Tabel 5. Uji $\mathrm{T}$ berpasangan kelompok 3 kali/minggu

\begin{tabular}{cc}
\hline & Sig. (1-tailed) \\
\hline HbA1c Awal - & \\
HbA1c Akhir & .258 \\
\hline
\end{tabular}

Berdasarkan hasil uji $\mathrm{T}$ tidak berpasangan, didapatkan nilai $\mathrm{p}=0,032$ $(<0,05)$ yang mennunjukkan terdapat perbedaan bermakna dari perubahan kadar HbA1c (selisih kadar Hb1Ac awal dan kadar HbA1c akhir) antara latihan 1 kali/minggu dan 3 kali/minggu.

Tabel 6. Uji $\mathrm{T}$ tidak berpasangan kelompok 1 kali/minggu dan 3 kali/minggu

\begin{tabular}{ccc}
\hline Test & Hasil & Keputusan \\
\hline $\begin{array}{c}\text { Independent } \\
\text { Sample T- } \\
\text { test }\end{array}$ & & \\
\hline
\end{tabular}

\section{BAHASAN}

Berdasarkan hasil penelitian terhadap 30 orang pasien DM Tipe 2 Klinik Hussada Sario Manado yang mengikuti senam Prolanis serta dibagi dalam dua kelompok yaitu 1 kali/minggu dan 3 kali/minggu, dengan perlakuan berupa senam Prolanis selama 60 menit, didapatkan bahwa subyek didominasi jenis kelamin perempuan (73\%). Umur rata-rata pasien berkisaran 50-70 tahun $(66,60 \%)$.

Terdapat perbedaan bermakna antara perbandingan kedua kelompok $(p=0,032)$. Perubahan kadar HbA1c kelompok 1 kali/minggu sebelum dan sesudah senam bermakna ( $\mathrm{p}=0,034)$ namun perubahan tersebut mengarah kearah negatif karena rerata perubahan kadar HbA1c meningkat 0,13\%. Perubahan kadar HbA1c kelompok 3 kali/minggu tidak bermakna $(p=0,25)$ namun rerata perubahan kadar HbA1c pada kelompok tersebut menturun 0,04\%. Jumlah responden yang mengalami 
penurunan kadar HbA1c pada kelompok 1 kali/minggu hanya 4 orang (27\%) saja sedangkan pada kelompok 3 kali/minggu 8 orang (53\%). Kadar HbA1c kelompok 1 kali/minggu juga mayoritas meningkat dengan jumlah responden 9 orang (60\%). Hal ini menunjukkan bahwa walau tidak terdapat perbedaan signifikan antara kadar HbA1c sebelum dan sesudah olahraga, senam Prolanis terbukti lebih efektif pada kelompok 3 kali seminggu.

Hasil dari suatu meta-analisis menunjukkan bahwa latihan fisik 150 menit per minggu kurang dari 12 minggu menurunkan kadar HbA1c sebesar 0,5\%. ${ }^{10}$ Penelitian dari Umpierre et al. ${ }^{11}$ menyatakan bahwa latihan teratur lebih dari 150 menit setiap satu minggu menurunkan HbA1c sebanyak 0,89\%, lebih banyak 0,53\% dari latihan fisik teratur kurang dari 150 menit setiap satu minggu yaitu $0,36 \%$. Hal ini juga penting sebab ADA menyatakan bahwa sekurang-kurangnya latihan fisik dilakukan 3 kali seminggu dengan total durasi 150 menit dengan syarat tidak boleh dilakukan lebih dari 2 hari berturut-turut. ${ }^{11-13}$ Senam Prolanis yang diadakan oleh BPJS berkisaran 60 menit, sehingga berdasarkan penelitian tersebut, akan lebih efektif bila latihan diadakan 3 kali per minggu dengan total durasi 180 menit.

Selama berolahraga, konsumsi oksigen meningkat 20 kali lipat dan lebih tinggi lagi pada otot yang sedang bekerja. Untuk mencukupi kebutuhan energi, otot rangka memakai simpanan glikogen dan trigliserida beserta asam lemak bebas. Untuk menjaga sistem saraf pusat, level glukosa darah teregulasi baik selama orahraga. Penurunan plasma insulin dan munculnya glukagon penting unttuk menaikkan produksi glukosa hepar selama latihan, meningkatkan plasma glukagon dan katekolamin yang merupakan kunci penting ${ }^{1,2,7}$.

Hasil tinjauan secara sistematik dan meta-analisis penelitian klinis mengenai efek intervensi latihan fisik yang terstruktur selama $\geq 8$ minggu pada kadar glukosa darah rata-rata dalam 2-3 bulan (HbA1c) menunjukkan terjadinya penurunan HbA1c yang signifikan setelah intervensi latihan fisik dibanding kelompok kontrol (7,65 vs. 8,31\%), dengan mempertimbangkan perbedaan mean $0,66 \%(\mathrm{P}<0.001){ }^{11}$

Kadar HbA1c menunjukkan nilai ratarata glukosa darah selama 3 bulan dan penurunan setiap 1\% HbA1c dihubungkan dengan turunnya insiden penyakit kardiovaskular sebesar 15\%-20\% dan komplikasi penyakit mikrovaskular sebesar 37\%. ${ }^{14}$ Latihan fisik meningkatkan kemampuan insulin untuk mengaktifkan transport gula ke otat yang sudah diberi latihan dan efek ini dapat bertahan beberapa jam setelah latihan fisik. ${ }^{1,2,7}$ Ini membuktikan bahwa aktivitas fisik secara reguler merupakan hal penting dalam menangani DM Tipe 2.

Limitasi penelitian ini ialah singkatnya waktu penelitian yaitu hanya satu bulan, sehingga kurang efektif dalam mengukur efek senam Prolanis pada kadar HbA1c.

\section{SIMPULAN}

Berdasarkan hasil penelitian yang dilakukan di Klinik Hussada Sario Manado, penulis menarik kesimpulan bahwa terdapat perbedaan bermakna antara kadar HbA1c pasien DM Tipe 2 dengan frekuensi senam Prolanis $1 \mathrm{kali} /$ minggu dan 3 kali/minggu. Serta walau terdapat perubahan tidak bermakna, senam Prolanis 3 kali/minggu terbukti lebih efektif dalam menurunkan kadar HbA1c.

\section{SARAN}

Diharapkan pada penelitian berikutnya dapat dipakai variabel-variabel lain seperti pemakaian obat dan pola diet pasien.

\section{DAFTAR PUSTAKA}

1. Powers AC. Diabetes Mellitus. In: Longo DL, Faucy AS, Kasper DL, Hauser SL, Jameson JL, Loscalzo J, editors. Harrison's Internal Medicine (18th ed). United States of America: The McGraw-Hill Company, 2012; p. 2968-70, 2992.

2. Price SA, Wilson LM. Bab 10: Pankreas: 
metabolisme glukosa dan diabetes mellitus. In: Patofisiologi konsep klinis proses-proses penyakit (6th ed). Jakarta: EGC, 2005; p. 1260.

3. Purnamasari D. Diagnosis dan klasifikasi Diabetes Mellitus. In: Sudoyo AW, Setiyohadi B, Alwi Idrus, Simadibrata M, Setiati S, editors. Buku ajar ilmu penyakit dalam jilid III (5th ed). Jakarta: Internal Publishing, 2009; p. 1875-76, 1895.

4. Hasil Riset Kesehatan Dasar (Riskesdas), Jakarta: Badan Penelitian dan Pengembangan Kesehatan, Kementrian Kesehatan RI, 2013. Available from: www.depkes.go.id/resources/downloa d/general/Hasil\%20Riskesdas\%20201 3.pdf

5. PT Askes (Persero). Buletin Info Askes edisi Januari. Jakarta Pusat, 2011.

6. BPJS. Buku Panduan PROLANIS 2014 [diakses 5 Oktober 2015]. www.bkkbn.go.id/Documents/JKN/0 6-PROLANIS.pdf

7. Guyton AC, Hall JE. Bab 78: Insulin, glukagon dan diabetes mellitus. In: Buku ajar fisiologi kedokteran (11th ed). Jakarta: EGC, 2008; p. 1026.

8. Utomo MRS. Kadar HbA1c pada pasien diabetes mellitus tipe 2 di puskesmas manado kecamatan malalayang manado. eBM. 2015;3:2.

9. Yang Z, Scott CA, Tang J, Farmer AJ. Resistence exercise versus aerobik exercise for type 2 diabetes. Sports Med. 2013;10:13.

10.Duarte CK, Almeida JC, Merker AJ, Brauer FO, Rodriguez TC. Physical activity level and exercise in patients with diabetes mellitus. Rev Assoc Med Bras. 2011;58:216.

11.Umpierre D, Riberio PA, Kramer CK, Leita CB, Zucatti AT, Azevedo MJ, et al. Physical activity advice only or structured exercise training and association with HbA1c levels in type 2 diabetes. JAMA. 2011;305:1790-9.

12.Sigal RJ, Kenny GP, Wasserman DH, Sceppa C. Physical activity and type 2 diabetes. Diabetes Spectrum. 2005;18:89.

13.Bacchi E, Negri C, Bonora E, Moghetti $P$. Influence of acute bouts of exercise on blood glucose in type 2 diabetic patients, as measured by continuous glucose monitoring systems. J Diabetes Metab. 2013;4:1.

14. Church ST, Balir SN, Cocreham S, Johannsen N, Johnson W, Kramer $\mathbf{K}$, et al. Effects of aerobic and resistance training on hemoglobin a1c levels in patients with type 2 diabetes. JAMA. 2011;304:8. 